\title{
The Enlightenment of Natural Dialectics to the Development of Rural Tourism Resources in Huangsi Town, Xingtai, Hebei
}

\author{
Yanming Zhang \\ School of Economics and Management, Zhejiang Ocean University, Zhoushan, Zhejiang, 316022, China
}

\begin{abstract}
With the continuous progress and development of human productivity, the relationship between man and nature is undergoing phased changes. From understanding nature, transforming nature to now revering nature, it reflects the process of historical development and evolution. Xingtai Huangsi Town is a provincial-level historical and cultural town in Hebei Province with a unique geographical location. It is a typical "mountain town". The terrain in the east is flat and the resources in the west are very rich. In recent years, rural tourism in Hebei Province has experienced a wave of rural tourism development. However, due to serious problems such as the fragile ecological environment, the development of rural tourism resources has to use the theory and method of natural dialectics to look at the relationship between man and nature.
\end{abstract}

Keywords: Dialectics of nature, Countryside tour, Huangsizhen.

\section{The Basic Overview of Huangsi Town}

Huangsi Town is located in the north-central part of Xingtai County, Hebei Province, 18 kilometers away from the urban area of Xingtai. The ancient town is surrounded by mountains on three sides, like a small basin in the mountains. The Jinyu River and Yinyu River pass through the town, and the unique geographical location surrounded by mountains on three sides has created the "Yuquan Sunset", one of the eight scenic spots in Xingtai. Huangsi Town is rich in resources. More than 20 kinds of minerals have been discovered, mainly including: gypsum, quartz sandstone, garnet, kyanite, iron, graphite, etc. Relying on rich mineral resources, the industry has formed building materials, gypsum mining, quartz sandstone and garnet processing as the leading industries. Complete agricultural and sideline products, rich in wheat, cotton, peanuts, fresh peaches, apples, walnuts, persimmons, jujubes. Huangsi Town has a total area of 155 square kilometers and a resident population of 33,336 people. It has jurisdiction over Huangsi, Dongyangwo, Bafang, Xiqingshan, Nanqingshan, Tancun, Guocun, Xucun, Su Village, Xiyangwo, Talk, Warm River, Dongsi, Xiaohe, Shayu, Nanzhuang, Beizhuang, Dongzhangma, Xizhangma, Guanyinkeng, Naoshang, Mojiagang, Cuijiazhuang, Shixianghe, Dabaigong, Xiaobaigong, Yaozigou, Zhang'anbei, Heshanggou, Junliuzhuang, Dongzhaozhuang, Xizhaozhuang, Fenglaiyu, Heinao, Yuegou, Hanmeihua, Shangmeihua, Limeihua, Huangmeihua, Lujiadong, Yuanjiazhuang, Dongzhaigou, Weilu 43 administrative departments village. Villages are mostly distributed in small basins in the mountains. Huangsi Town has an ancient history. According to the "Xingtai County Chronicle", Huangsi, formerly known as Huangsidian, is located 18 kilometers northwest of Xingtai City. There is Yuquan Temple in the village. It is said that at the end of the Yuan Dynasty, Emperor Shun fled north and stayed in this temple. Later, Yuquan Temple was renamed Huang Temple, and the name of the village was also derived from this. The town has a history of more than a thousand years and has been rated as a provincial-level historical and cultural town in Hebei.

\section{The Rural Tourism Resources and Feature of Huangsi Town}

Compared with the villages in other regions of Hebei, Huangsi Town not only has rich historical and cultural heritage resources, but also has beautiful and colorful northern mountain landscapes with unique charm. The village of Huangsi Town is rich in natural and cultural tourism resources. There is Yuquan Temple, which was built in the Tang Dynasty. In the Yuquan Temple, there are three Tang cypresses. After more than 1,200 years of wind and rain, the bird cypresses are more than 20 meters high and tall and straight. Vigorous, vigorous, and lush all year round. In and around Yuquan Temple, there are a large number of stone carvings of the past dynasties, which can be divided into pillar foundations, stone steps, railings, Yuquan drainage taps, etc. for construction; there are stele carvings, which are divided into two types: scripture buildings and stone steles; Stone carvings related to Buddhism, such as offering tables, stone Buddha statues, etc. In Longshan, south of Yuquan Temple, there are still some cliff stone carvings, three of which are located on the mountainside of the north slope of Longshan. the upper part is slightly round, the standing Buddha is on the lotus seat, with backlight, the head is damaged, and the preservation is basically intact. Huangsi Town has experienced more than 500 years of history, contains rich history and culture, is a solidified cultural classic, and has high historical value and ornamental value for the study of architectural history, folk history, etc. There are many types of buildings and various forms. There are all kinds of stone farmhouses, magnificent and tall stone attics, and courtyards with peculiar layouts. People in Huangsi Town are accompanied by stone every day and night, and stone culture is displayed everywhere in the town. Stone Residential Residence The residential building layout of Huangsi Town is flexible and diverse. Except for the unified planning of the foundation street, the rest are arranged freely according to the terrain. The built houses are based on individuality and commonality as the second. Due to different financial resources, houses appear to be of different heights, depths and widths. Some primitive stones on the walls, some with few 
traces, are rough and unrestrained, showing the primitive and simple architectural style and characteristics of farm buildings, which can be described as representatives of rural buildings. Huangsi Village is a famous historical and cultural town in Hebei Province. Carrying forward the historical and cultural advantages of Huangsi Village and focusing on developing tourism economy is the only way to revive Huangsi Village. The planning focuses on the protection of Yuquan Temple, Jinyu River and ancient bridges, treasure wells, ancient lanes, Wang Family Courtyard, Yao Family Courtyard, Qipan Mountain and other elements that embody the characteristics of the ancient town.

In terms of natural scenery, Huangsi Town is not inferior. Huangsi Town is prosperous because of water. There is a living spring in front of Yuquan Temple, which is called Yuquan Pond. "There is a scene in front of Huangsi Village, and there is a well in front of every house", "The spring water flows around the street, you don't have to worry about eating and drinking", this is a folk song circulating in the area of Huangsi Village, 40 miles west of Xingtai City. In the historical Huangsi Village, there are green trees everywhere on the mountain, and clear springs gurgling under the mountain. Outside the village, there are springs dingdong and small bridges and flowing water everywhere. Yuquan Pond is about 30 meters in diameter and 10 meters deep, like a large round mirror. The spring water is inexhaustible for thousands of years, not only for the drinking of thousands of people in the whole village, but also for irrigation of thousands of acres of fertile fields. Whenever the sun sets in the west, the sun reflects on this spring, sparkling spring water and the endless Taihang Mountains come into view. This is the sunset landscape of Yuquan, one of the eight scenic spots in ancient Xingtai.

\section{The Enlightenment of Dialectics of Nature to Development of Rural Tourism Resources in Huangsi Town}

Dialectics of Nature is about the general laws of nature and the development of science and technology, as well as the fundamental method and way of thinking for human beings to understand and transform nature. Dialectics of nature is also an important component of Marxist philosophy, an important guiding ideology for human beings to understand and transform nature, and it advocates the harmonious development of man and nature. Because it meets the requirements of the sustainable development thought advocated in today's world, the thought of dialectics of nature has been applied to all walks of life in today's society. The development of rural tourism resources for ethnic minorities in Guizhou is the dialectical unity of the relationship between man and nature. Therefore, the dialectics of nature has some enlightenment for the development of rural tourism resources of ethnic minorities in Guizhou.

\subsection{Using SWOT Analysis to Estimate the Development of Rural Tourism Resources}

Huangsi Town is located at the junction of the North China Plain and the Taihang Mountains. In recent years, with the increase of population and industrial development, ecological problems have become more and more acute. In addition, consideration should be given to whether the development of rural tourism resources and the development of rural tourism will damage the history, culture and ancient dwellings of the tourism resource areas; what is the carrying capacity of the tourism destination, and will it affect the normal life of the local people? whether the tourist destination is accessible, etc. Therefore, SWOT analysis should be used to investigate and evaluate the advantages, disadvantages, opportunities and threats of the development of rural tourism resources in Huangsi Town, Xingtai, Hebei Province, and then make statistical analysis to provide a basis for whether or not rural tourism is developed.

\subsection{The Scientific and Rational Development to Achieve Sustainable Development}

Edward Inskop once pointed out that sustainable tourism development includes appropriate use and appropriate actions to strengthen the landscape characteristics of the land, local awareness, community personality and site development opportunities. In the development of rural tourism resources and rural tourism in Huangsi Town, Xingtai, Hebei, the guiding ideology of sustainable development should also be taken as the main guiding ideology, and this issue should be viewed from a long-term perspective. For natural and cultural tourism resources, especially natural tourism resources, destructive and blind development should be avoided, so as not to bring excessive burden or damage to nature, and cause the vegetation in the area to be difficult to restore or permanently damaged. Occupational planning and management are relatively lacking, and traditional buildings have been destroyed by new types of buildings: Since the reform and opening up, the people's growing way of life can no longer be satisfied by the traditional living environment, so a number of rebuilt and reconstructed new houses have appeared. Therefore, the emergence of new materials and new styles has destroyed the pattern of old-fashioned buildings. Even if people realize the importance of ancient buildings, they only have a simple distinction between new houses and old houses, and there is no professional planning. As a result, there are neither isolation areas nor transition areas in the old and new areas. In the long run, it will make it difficult to continue the traditional ancient style. Most of the old houses are in disrepair, and maintenance and development are in a dilemma: for a long time, the houses in Huangsi Town were owned by individuals, and maintenance and repairs were arranged independently. The dilapidation of old houses makes people more advocating to own new houses, so many old houses are abandoned, and some are even used as cowsheds, etc. These phenomena further accelerate the damage of old houses. The entry of foreign cultures can easily lead to changes in the traditional way of life and the concept of life: the people of Huangsi Town have lived in a stable and peaceful atmosphere for centuries. In recent years, with the continuous influx of foreign residents, the way of life of local people will inevitably be affected, which greatly reduces the local history, culture and value. For the unique spring water and ancient village culture of Huangsi Town, we must also pay attention to it. Preserving the culture of a place is the embodiment of the current cultural heritage and national spirit. We must respect cultural customs, respect their originality and uniqueness, not destroy or excessively commercialize 
them, but protect them. On the basis of ensuring the sustainable development of natural and cultural tourism resources in ethnic minority villages, combined with the investigation, analysis and evaluation of tourism resources, conduct tourism resource rating, resource development, route planning, tourist and environmental capacity calculation, infrastructure for local rural tourism improvement, etc., to achieve sustainable development.

\section{Epilogue}

Dialectics of nature plays an important role in guiding human beings to understand and transform nature, so it is valued by major industries in today's society. Huangsi Town, Xingtai, Hebei Province is rich in rural resources, suitable for climate, and has unique natural and cultural landscapes. However, due to the lack of understanding of the natural environment and the influence of various other objective factors, there have been some problems that cannot be ignored in the development of its tourism resources, which will cause and serious adverse consequences. This paper puts forward some development and development suggestions on the development of rural tourism resources in Huangsi Town, Xingtai, Hebei Province, according to the relevant ideas of dialectics of nature, mainly including SWOT analysis and sustainable concepts, hoping to provide reference for future development.

\section{References}

[1] Feng Jicai. The predicament and the way out of traditional villages - Traditional villages are a kind of cultural heritage[J]. Folk Culture Forum, 2013(1):7-12.

[2] Zhang Jie. "Reinforcement" and "Renewal" of rural cultural heritage protection under rural revitalization-Also on the interpretation of the rural development system in the 40 years of reform and opening up [J]. Planners, 2018, 34(10):26-31.

[3] Jiang Heping. Implementation of rural revitalization strategy and development model that can be used for reference $[\mathrm{J}]$. Agricultural Economics and Management, 2017(6):17-24.

[4] Zhou Mingkun. On the inspiration of dialectics of nature to modern ecological architecture design [J]. Sichuan Cement, 2015(10):138.

\section{Author Profile}

Yanming Zhang (1997-), Graduate student at the School of Economics and Management, Zhejiang Ocean University. Born in Xingtai City, Hebei Province, professional name is Rural Development. 